\title{
O gênero Eustala (Araneae, Araneidae) no sul do Brasil: duas espécies novas, descrições complementares e novas ocorrências
}

\author{
Maria Rita M. Poeta, Maria Aparecida L. Marques \& Erica Helena Buckup
}

Museu de Ciências Naturais, Fundação Zoobotânica do Rio Grande do Sul, Rua Dr. Salvador França, 1427, 90690-000 Porto Alegre, RS, Brasil. (maria.poeta@acad.pucrs.br; maria-marques@fzb.rs.gov.br; erica@fzb.rs.gov.br)

\begin{abstract}
The genus Eustala (Araneae, Araneidae) in southern Brazil: two new species, complementary descriptions and new records. Eustala levii sp. nov. and E. palmares sp. nov. are described from Rio Grande do Sul, Brazil, based on both sexes. The males of E. albiventer (Keyserling, 1884), E. taquara (Keyserling, 1892), and E. photographica Mello-Leitão, 1944 are described for the first time and the females are redescribed. Eustala sanguinosa (Keyserling, 1893) is synonymized with E. albiventer. Additionally, E. photographica, described from Argentina, is newly recorded from Brazil. New records are provided for E. minuscula (Keyserling, 1892) and E. saga (Keyserling, 1893).
\end{abstract}

KEYWORDS. Spiders, taxonomy, geographical distribution, Neotropical.

RESUMO. Eustala levii sp. nov. e E. palmares sp. nov. são descritas do Rio Grande do Sul, Brasil, com base em ambos os sexos. Os machos de E. albiventer (Keyserling, 1884), E. taquara (Keyserling, 1892) e E. photographica Mello-Leitão, 1944, são descritos pela primeira vez e as fêmeas são redescritas. Eustala sanguinosa (Keyserling, 1893) é considerada sinônimo de E. albiventer. Eustala photographica, descrita da Argentina, é registrada pela primeira vez para o Brasil. Novas ocorrências ampliam a distribuição geográfica de $E$. minuscula (Keyserling, 1892) e E. saga (Keyserling, 1893).

PALAVRAS-CHAVE. Aranhas, taxonomia, distribuição geográfica, Neotropical.

O gênero Eustala, proposto por Simon (1895) com a designação da espécie-tipo Epeira anastera Walckenaer, 1841, é conhecido apenas para o continente americano. Essas aranhas vivem na vegetação arbustiva e arbórea, tecendo teias orbiculares quase verticais (LEvI, 1977).

LeVI (1977) revisou as espécies norte e centroamericanas de Eustala, redefinindo os caracteres diagnósticos do gênero. $\mathrm{O}$ palpo dos machos apresenta única macrocerda na patela e apófise média cônica, longa e esbranquiçada. Geralmente, a apófise terminal é longa, afilada e esclerotinizada e a subterminal é transparente com base semelhante a uma bolha e prolongamento apical. Em algumas espécies, ambas as apófises são reduzidas. O condutor varia conforme a espécie. As fêmeas têm epígino com escapo projetado anteriormente.

$\mathrm{O}$ abdômen, geralmente subtriangular, tem padrão de coloração com duas faixas longitudinais em ziguezague em "V", configurando um fólio. Este padrão, comum à maioria das espécies, dificulta a associação de machos e fêmeas, fato constatado por CHickeRING (1955) ao descrever 26 espécies da América Central, das quais apenas duas com base em ambos os sexos, e também comentado por LEVI (1977). A coloração também varia conforme o grau de pigmentação, mostrando aspecto aparentemente diferenciado em exemplares de uma mesma espécie.

Platnick (2010) relacionou 91 espécies para o gênero, das quais 19 têm registros para o Brasil. Desse elenco, seis foram descritas do Rio Grande do Sul: Eustala minuscula (Keyserling, 1892) e E. saga (Keyserling, 1893), conhecidas por ambos os sexos; E. albiventer (Keyserling, 1884), E. taquara (Keyserling, 1892), E. ulecebrosa (Keyserling, 1892) e E. sanguinosa (Keyserling, 1893) conhecidas apenas pelas fêmeas. Mello-Leitão (1944) descreveu E. photographica, com base em fêmea de Buenos Aires, Argentina. Levi (2007) examinou e ilustrou os espécimes-tipo de espécies centrosul-americanas, disponibilizando suas ilustrações na internet, o que proporcionou reconhecer várias espécies.

O objetivo é descrever duas espécies novas de Eustala com base em ambos os sexos, apresentar os machos de E. albiventer, E. taquara e E. photographica, até o momento desconhecidos, e ampliar a área de distribuição de E. minuscula e E. saga.

\section{MATERIAL E MÉTODOS}

As fêmeas de Eustala têm o epígino retraído na área epigástrica, o qual deve ser puxado com auxílio de um alfinete entomológico, a fim de que toda a estrutura fique exposta para a elaboração de ilustrações nas vistas ventral, posterior e lateral. Ilustrações foram realizadas sob estereomicroscópio com câmara-clara. A terminologia do palpo e do epígino segue Levi (1977). Medidas são expressas em milímetros.

O material examinado pertence à coleção de aranhas do Museu de Ciências Naturais (MCN), Fundação Zoobotânica do Rio Grande do Sul, Porto Alegre (E. H. Buckup, curadora).

\section{Eustala levii sp. nov. (Figs 1, 8-13)}

Tipos. Holótipo o e parátipo , São Francisco de Paula (Fazenda Três Cachoeiras), 05.XI.1998, A. B. 
Bonaldo col. (MCN 29718). Parátipos: + , São Francisco de Paula (Fazenda Três Cachoeiras), 05.XI.1998, L. Moura col. (MCN 29716); ; (Usina Passo do Inferno), 16.XII.1999, A. B. Bonaldo col. (MCN 31715); ð, (Passo dos Bugres), 04.XI.1998, L. Moura col. (MCN 29705); o’, Triunfo, 21.IX.1989, E. H. Buckup col. (MCN 18660). Todos do Rio Grande do Sul, Brasil.

Etimologia. O nome específico é uma homenagem ao aracnólogo Herbert W. Levi pela sua enorme contribuição ao conhecimento da família Araneidae.

Diagnose. O palpo do macho de Eustala levii (Figs $8,9)$ distingue-se daqueles da maioria das espécies do gênero com apófise terminal longa e afilada, pelo êmbolo com base longa e larga e condutor projetado lateralmente, em vista mesial (Fig. 8). O epígino (Figs 10-12) distinguese pelo escapo anelar com base retangular, mais larga do que longa, com brusco estreitamento mediano e prolongamento apical, em vista ventral (Fig. 10); placa mediana com conspícua constrição junto às aberturas, em vista ventral (Fig. 10).

Descrição. Macho (holótipo). Carapaça amarela com manchas castanhas. Esterno amarelo-claro com margem cinza. Pernas amarelas com bandas de manchas castanhoclaras. Abdômen oval, mais longo do que largo, com maior largura nos ângulos laterais anteriores, pouco salientes, e com pequeno ápice posterior; dorso branco, fólio quase indistinto, duas pequenas manchas circulares pretas nos ângulos laterais e área mediana anterior e posterior castanho-escuras. Ventre preto com mancha mediana branca.

Medidas. Comprimento total 5,6. Comprimento da carapaça 2,7, largura 2,3. Pernas, fórmula 1243. Comprimento da perna I: fêmur 4,5; patela + tíbia 5,2; metatarso 3,0; tarso 1,0; comprimento total 13,7. Patela + tíbia II 3,7; III 1,6; IV 2,7.

Fêmea (parátipo, MCN 29718). Colorido semelhante ao do macho, exceto carapaça com seis pontos castanhos e abdômen subtriangular com ângulos laterais mais acentuados (Fig. 13).

Medidas. Comprimento total 7,1. Comprimento da carapaça 3,2, largura 2,6. Pernas, fórmula 1243. Comprimento da perna I: fêmur 4,5; patela + tíbia 5,4; metatarso 3,3 ; tarso 1,3 ; comprimento total 14,5. Patela + tíbia II 2,4; III 1,6; IV 2,4.

Variação. Machos ( $\mathrm{n}=5)$ : comprimento total: 5,5-5,6; carapaça: 2,7-3,0; largura: 2,2-2,4. Fêmeas $(n=5)$ : comprimento total: 6,4-7,6; carapaça: 2,6-3,2; largura: 2,02,6 . As manchas da carapaça podem ser mais ou menos pigmentadas ou ausentes. Ápice do abdômen, às vezes, inconspícuo e o fólio pode ser nítido ou esmaecido.

Distribuição. Brasil (Paraná, Santa Catarina e Rio Grande do Sul) (Fig. 1).

Material examinado. BRASIL, Paraná: Colombo, on, 02.XII.1990, A. D. Brescovit col. (20652); Santa Catarina: Rancho Queimado, o', 15-18.XI.1995, A. B. Bonaldo col. (26777); Rio Grande do Sul: Caxias do Sul,, , 20.XI.1993, L. Moura col. (44369); Canela, o', 26.XII.1974, A. A. Lise col. (2456); 우, 15.XII.1999, A. Franceschini col. (31767); São Francisco de Paula, o', 19.XI.1997, E. H. Buckup col. (28823); o', ᄋ, 04-06.XI.1998, A. B. Bonaldo col. $(29670,29701)$; Montenegro, , 06.X.1977, A. A. Lise col. (6758); Triunfo (Parque Copesul de Proteção Ambiental), O', ㅇ, 24.X.1989, E. H. Buckup col. (18888, 18890); 7. 24.X.1989, A. D. Brescovit col. (18894); 2 o', 28.XI.1989, A D. Brescovit col. (19113); , 30.XI.2004, R. Ott col. (38191);
07.XII.2005, A. Barcellos col. (40115); Gravataí, O. 25.XI.1998, M. A. L. Marques col. (29799); Eldorado do Sul (Parque Estadual do Delta do Jacuí), + 26.I.1999, L. Moura col. (30186); ठ7, 12.XI.1998, L. Moura col. (29741); o’, +, 12.XI.1998, A. H. Silva col. (29746); Porto Alegre (Morro Santana), +, 28.X.1998, R. A Ramos col. (18975); Viamão (Estação Fitotécnica de Águas Belas), 18.X.1985, 2 q, A. D. Brescovit col. (14462, 45414); Tapes, + , 17.XII.2003, Equipe Probio col. (36781); Capão do Leão (Horto Botânico Irmão Teodoro Luís), O’, 8 P, E. N. L. Rodrigues col. (46399); Arroio Grande, 2 o', ㅇ, 16.XI.2007 (46461); o , 10.III.2008 (46471), coletados por E. N. L. Rodrigues; Rio Grande (Estação Ecológica do Taim), ơ, 10.IV.1986, M. A. L. Marques col. (45320)

\section{Eustala palmares sp. nov.}

(Figs 2, 14-19)

Tipos. Holótipo o e parátipo $\odot$, Palmares do Sul, Rio Grande do Sul, Brasil, 11.XI.2003, Equipe Probio col (MCN 36612). Parátipos: 16 ơ, 19 (MCN 46637) e $4 \sigma^{7}, 8$ \% (MCN 46638), mesmos dados do holótipo; 8 ơ, 5 \%, Santo Antônio da Patrulha, 19.VII.2000, A. B. Bonaldo col. (MCN 33133); o’, ॰, Eldorado do Sul, 29.X.1998, A. B. Bonaldo col. (MCN 29663) e $2 \sigma^{\prime}, 2$, Eldorado do Sul, 29.X.1998, A B. Bonaldo col. (MCN 46511), todos do Rio Grande do Sul, Brasil.

Etimologia. O substantivo específico refere-se à localidade-tipo.

Diagnose. O macho de Eustala palmares distinguese das espécies similares, com apófise terminal longa e afilada e condutor com concavidade circular anterior, pela apófise terminal com uma quina na metade apical, pela forma do prolongamento posterior do condutor, pelas rugosidades na margem apical do tégulo e pela projeção tegular subtriangular (Figs 14, 15). As fêmeas separamse pelo epígino (Figs 16-18) com escapo anelado, com saliência mediana e prolongamento apical estreito, em vista ventral e lateral (Figs 16, 18); porção basal do escapo larga, em vista lateral (Fig. 18).

Descrição. Macho (holótipo). Carapaça amarela, região cefálica manchada de cinza com vestígio de pigmento branco mediano-longitudinal, região torácica com quatro pontos cinza. Esterno amarelo com margens escurecidas. Pernas amarelas com bandas castanhoescuras. Abdômen oval, mais longo do que largo, com ápice posterior arredondado; dorso com fólio rodeado de retículos brancos e porção anterior com faixa transversal escurecida e mancha central preta; ventre com larga faixa longitudinal castanha e pigmento branco mediano.

Medidas. Comprimento total 3,3. Comprimento da carapaça 1,7, largura 1,4. Pernas, fórmula 1243. Comprimento da perna I: fêmur 2,4; patela + tíbia 2,9; metatarso 1,5 ; tarso 0,7 ; comprimento total 7,5. Patela + tíbia II 2,0; III 1,0; IV 1,7.

Fêmea (parátipo, MCN 36612). Carapaça como no macho, mas região cefálica delimitada por pigmento branco. Abdômen subtriangular com ângulos laterais anteriores desenvolvidos e ápice posterior arredondado; dorso com abundante reticulado branco e fólio (Fig. 19).

Medidas. Comprimento total 5,0. Comprimento da carapaça 1,9, largura 1,5. Pernas, fórmula 1243. Comprimento da perna I: fêmur 2,5; patela + tíbia 2,9; metatarso 1,7 ; tarso 0,7 ; comprimento total 7,8. Patela + tíbia II 2,1; III 1,1; IV 1,7. 
Nota. Vários machos e fêmeas foram coletados juntos em Palmares do Sul, Pelotas e Arroio Grande.

Variação. Machos ( $\mathrm{n}=5)$ : comprimento total: 3,2-4,0; carapaça: 1,7-1,9; largura: 1,4-1,6. Fêmeas $(n=5)$ : comprimento total: 3,1-5,0; carapaça: 1,6-2,0; largura 1,21,5. Carapaça e esterno com ou sem pigmento branco. $\mathrm{O}$ fólio do abdômen pode ser mais escurecido ou completamente esmaecido, ou ter um par de grandes manchas brancas anteriores; um espécime examinado apresenta dorso abdominal de coloração similar ao de $E$.
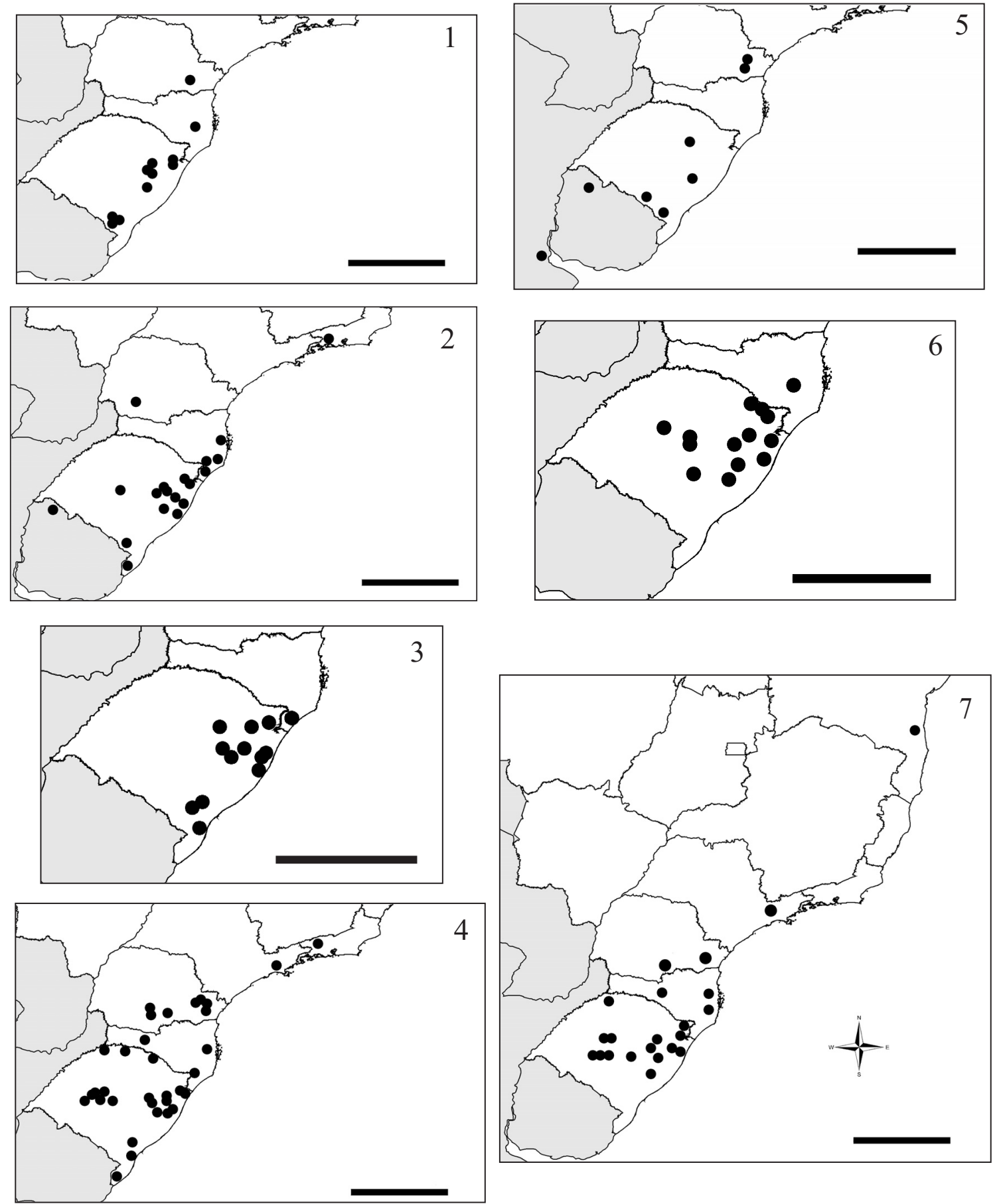

Figuras 1-7. Distribuição geográfica das espécies de Eustala: 1, E. levii sp. nov.; 2, E. palmares sp. nov.; 3, E. albiventer (Keyserling, 1884); 4, E. taquara (Keyserling, 1892); 5, E. photographica Mello-Leitão, 1944; 6, E. minuscula (Keyserling, 1892); 7, E. saga (Keyserling, 1893). Escalas: $500 \mathrm{~km}$. 
Governador Celso Ramos (Palmas das Gaivotas), ㅇ, 10-26.II.1993, L. Moura col. (22897); Garopaba (Praia do Siriú), O', 2830.X.1994, G. F. Grey col. (26149); Imbituba, , 28.II.1998, A. C. K. Ferreira. col. (29193); (Praia do Rosa), 4 +, 08-15.II.1998, A. B. Bonaldo col. (28951-28953); Rio Grande do Sul: Estrela Velha, O’, 19-21.I.2000, A. B. Bonaldo col. (32119); Canela, 3 , 06.III.1966, A. A. Lise col. (138, 837); Montenegro, 오 03.XI.1977, V. Pitoni col. (7127); Maquiné, क, 01.VIII.2007, E. N. L. Rodrigues col. (46469); São Leopoldo, 3 +, X.1973, C. J. Becker col. (27585, 27588); Triunfo (Parque Copesul de Proteção Ambiental), 9 , 28.V.2007, E. N. L. Rodrigues \& M. A. L. Marques col. (43384); Glorinha, ơ, 26.X.1997, L. Moura col. (28635); Santo Antônio da Patrulha, ơ, 19.VII.2000, A. B. Bonaldo col. (33134); Gravataí, O’, 15.III.1999, R. S. Araújo col. (30562); Eldorado do Sul, +, 12.XI.1998, L. Moura col. (29749); + , 26.I.1999, A. B. Bonaldo col. (30185); 2 , 12.XI.1998, A. Silva col. (29744); (Parque Estadual Delta do Jacuí), O', 05-07.I.2000, A. B. Bonaldo col. (45699); o', + , 10, 26.VIII.1999, A. B. Bonaldo col. (31450, 31484); O', 4 +, 27.X.1998, A. B. Bonaldo col. (29753, 29755, 29756); O', 27.X.1998, L. Moura col. (29762); 2 웅 27.X.1998, A. Silva col. (29763); ơ, 16.X.1999, A. Franceschini col. (31699); O', 13.VII.1999, A. Franceschini col. (31376); O’, 22.VII.1999, A. B. Bonaldo col. (31407); O’, 15.IV.1999, L. Moura col. (45413); Guaíba, ㅇ, 14.IV.1988, A. D. Brescovit col. (17694); ơ, 01.VIII.1986, A. D. Brescovit col. (15514); Porto Alegre (Reserva Biológica do Lami), O’, II.2000, L. E. C. Schmidt col. (37718); 2 , VIII.2000 (37690); O, ㅇ, 19-22.II.2001 (37691); 2 o., 4 ㅇ, 13, 14.VI.2001 (37693, 37719, 44897); 오, 11-13.V.2001 (37707); O', 01, 02.II.2002 (37712), todos coletados por E. L. C. Silva \& C. E. Ferro; Viamão, +, 08.X.1997, L. Moura col. (28514); Barra do Ribeiro, + , 16.I.2003, R. S. Araújo col. (35683); Palmares do Sul, 26 ơ, 37 ㅇ, 11, 12.XI.2003, Equipe Probio col. (36612; 36617); (Ilha Grande, Lagoa do Casamento), $20^{\prime}, 10$, 8 10.IV.2003, Equipe Probio col. (35657, 35276, 35387, 35389, 35392, 35489); (Lagoa dos Gateados), 5 ơ , + , 07.IV.2003, Equipe Probio col. (37303); 3 o', 2 ㅇ, 14.XI.2003, Equipe Probio col (36625); Capivari (Lagoa do Capivari), 15 \&, 20.V.2004, Equipe Probio col. (37375); Tapes (Pontal), + , 18.II.1977, E. H. Buckup col. (5197); ㅇ, 17.II.1977, H. Bischoff col. (5246); o', 15.V.2003 (37305); +, 19.XII.2003, Equipe Probio col. (36795); Pelotas, 6 o', 8 ㅇ, 25, 26.IX.1975, A. A. Lise col. (3459, 4084, 45713); Capão do Leão (Horto Botânico Irmão Teodoro Luís), 4 \%, 10.IX.2001, E. N. L. Rodrigues col. (44421); Rio Grande (Estação Ecológica do Taim), +, 15.X.1985, H. A. Gastal col. (13528); 2 o', 2 ㅇ, 15.X.1985, A. A. Lise col. (13665, 13667, 13702); +, 15 17.X.1985, M. Rosenau col. (13730, 13732); O’, ㅇ, 15, 16.X.1985, M. A. L. Marques col. $(45715,13767)$; o', 4 क, 16, 17.X.1985, E. H. Buckup col. (13510, 13656, 13657, 44986); O', 16.X.1985, C. J. Becker col. (13817); $\bigcirc^{7}, 5$ ㅇ, 28.XI.1985, M. Rosenau col $(13858,13859,13881,13882,13888)$; 3 ㅇ, 28.XI.1985, M. A L. Marques col. (13887, 13889); 2 O’,, , 28.XI.1985, H. A. Gastal col. (13976, 13977); 6 O $^{7}, 15$ क , 04-17.XII.1985, A. A. Lise col. (14190-14196, 14198-14200, 14224, 14225, 44980); 4 +, $07-$ 09.IV.1986, C. J. Becker col. (14678, 14679, 14685); 4 ơ, 4 ,

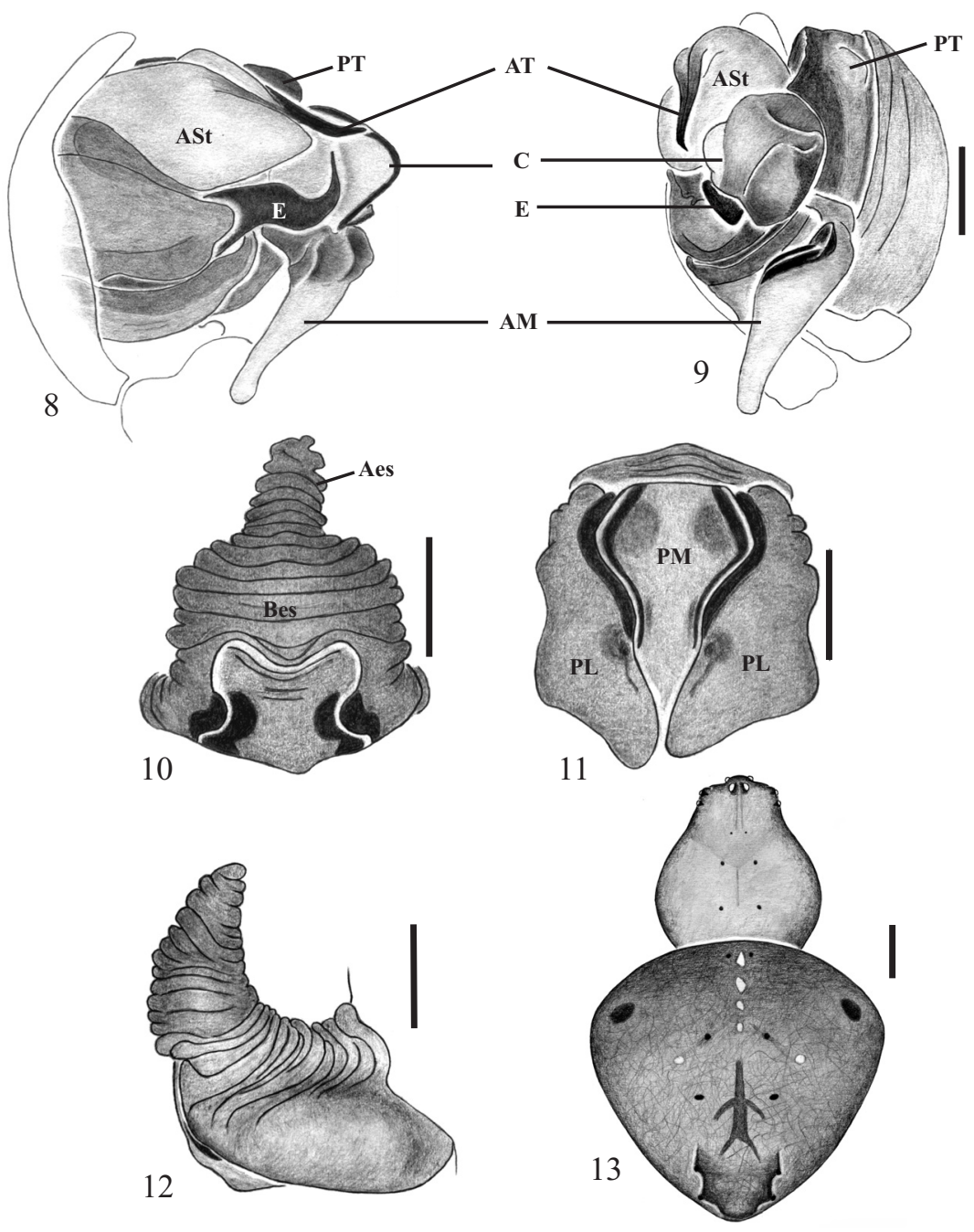

Figuras 8-13. Eustala levii sp. nov., palpo: 8, mesial; 9, ventral; epígino: 10, ventral; 11, posterior; 12, lateral; 13, corpo da fêmea (Aes, ápice do escapo; AM, apófise média; ASt, apófise subterminal; AT, apófise terminal; Bes, base do escapo; C, condutor; E, êmbolo; PL, placa lateral; PM, placa mediana; PT, projeção tegular). Escalas: Figs 8-12, 0,25 mm; Fig. 13, $1 \mathrm{~mm}$. 
07-09.IV.1986, M. Rosenau col. (14904, 14976,14977, 45340); +, 08.IV.1986, E. H. Buckup col. (14765); 2 o, 10 ㅇ, 0810.IV.1986, M. A. L. Marques col. (14907, 15003); 3 o', 8 क, 09, 10.IV.1986, E. H. Buckup col. (14658, 14659, 14963, 14964, 14681, 14682, 45405); 3 o', 6 ㅇ, 09.IV.1986, A. A. Lise col. (14646, 14647, 14993, 45319, 45403); 6 o $^{2}, 14$ ㅇ, 01, 02.IX.1986, A. A. Lise col. $(15653,15655,15658,15660,15663-15666) ; 6$ ơ, 4 †, 01, 02.IX.1986, M. Rosenau col. (15646-15648, 15673, 15674, 45412); 4 ठ, 6 ९, 02.IX.1986, M. A. L. Marques col. (15626-15630, 15632-15634, 45316); 4 ơ', 2 , 02.IX.1986, E. H. Buckup col. (15701-15704); 2 ơ, 2 , 02, 07.IX.1986, H. A. Gastal col. (15709, 15712, 45401); O’, , 04.XI.1986, E. H. Buckup col. (15954, 15994); 21 O̊, 37 , 02, 04.XII.1986, M. Rosenau col. (16300, 16490, 45020, 45314, 45402); $q$, 02.XII.1986, A. D. Brescovit col. (45040); 3 ơ, 7 \%, 04.XII.1986, E. H. Buckup col. (16328); + , 04.XII.1986, C. J. Becker col. (16616); 2 万’, 3 9, 04.XII.1986, M. A. L. Marques col. (45410); †, 04.XII.1986, M. C. Moraes col. (45411); ơ 2 9, 07.I.1987, A. A. Lise col. (16655-16657); Arroio Grande, 2 ơ, 2 \&, 30.I.2008 (46416); ㅇ, 10.III.2008 (46420); ㅇ, 25.IV.2008 (46417), coletados por E. N. L. Rodrigues; Santa Vitória do Palmar (Estação
Ecológica do Taim), 2 ९, 26.XI.1985, M. Rosenau col. (14044, 14045); , 26.XI.1985, H. A. Gastal col. (14092); 2 ㅇ, 26.XI.1985, M. A. L. Marques col. (14125, 14126); ㅇ, 05.IV.1986, E. H. Buckup col. (45407); O, 3 +, 09.IV.1986, M. Rosenau col. (14827, 45408); ㅇ, 09.IV.1986, A. A. Lise col. (14863); 2 ○', 2 , 09.IV.1986, M. A. L. Marques col. (14833, 45409); ㅇ, 02.IX.1986, E. H. Buckup col. (15762); ㅇ, 02.IX.1986, M. Rosenau col. (15716); ㅇ, 02.IX.1986, M. A. L. Marques col. (15718); 2 , 02.IX.1986, A. A. Lise col. (15760); 3 9, 03.XII.1986, M. A. L. Marques col. (16408); O', 3 ค, 03.XII.1986, A. D. Brescovit col. (16419); 2 ○, 6 \%, 03.XII.1986, M. Rosenau col. (16428, 45406); 2 O', 03.XII.1986, E. H. Buckup col. (16446). URUGUAI, Artigas: Artigas, ㅇ, 13, 14.X.1995, L. Moura col. (46800).

\section{Eustala albiventer (Keyserling, 1884) \\ (Figs 3, 20-24)}

Epeira albiventer KeyserLing, 1884:651, est. 21, fig. 3, holótipo fêmea, Santa Isabela (atualmente, Santa Isabel do Sul, $2^{\circ}$ distrito do município de Arroio Grande), Rio Grande do Sul, Brasil, depositado no National Museum of Ireland e examinado por $\mathrm{H}$.
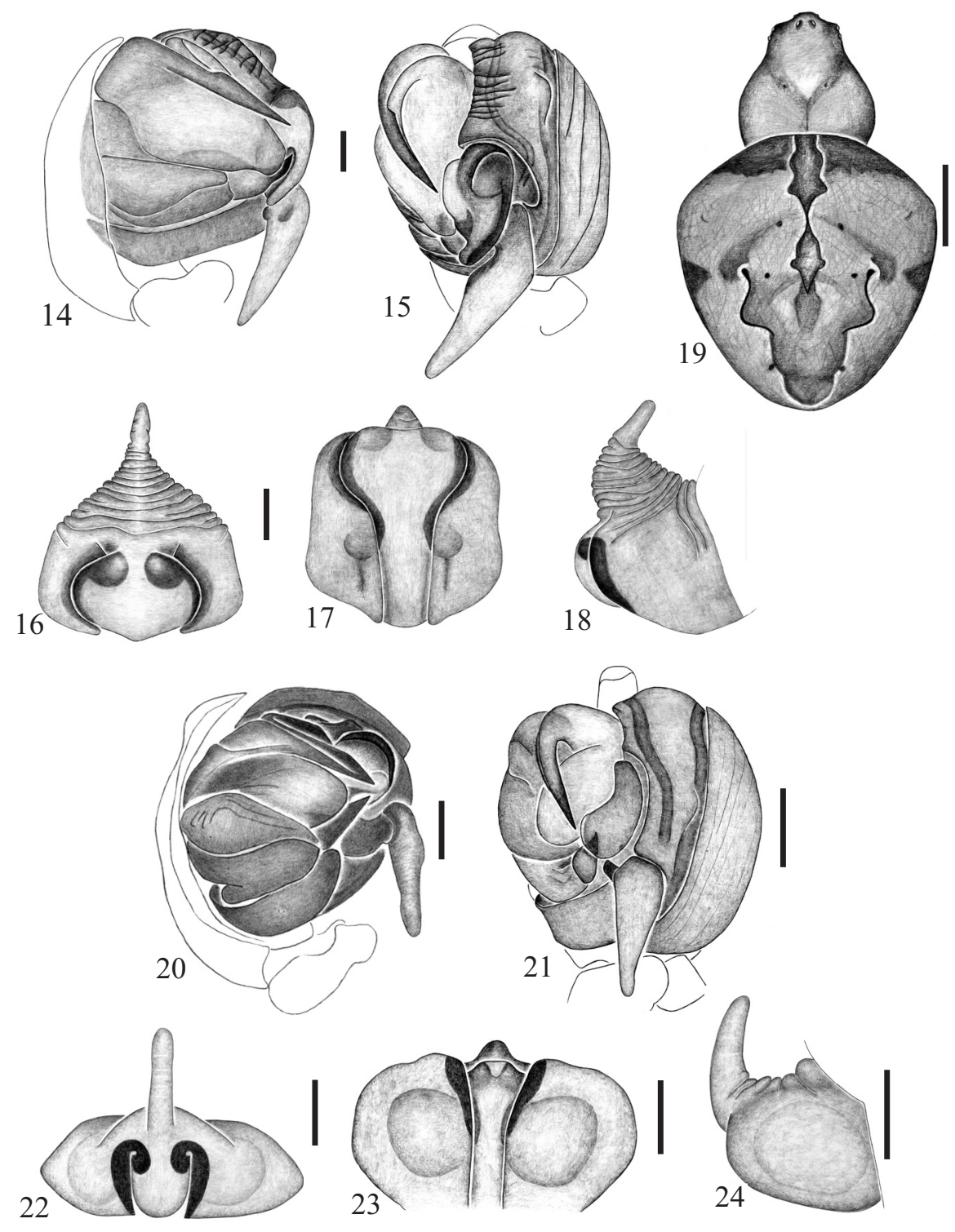

Figuras 14-24. Eustala palmares sp. nov., palpo: 14, mesial; 15, ventral; epígino: 16, ventral; 17, posterior; 18, lateral; 19, corpo da fêmea. Eustala albiventer (Keyserling, 1884), palpo: 20, mesial; 21, ventral; epígino: 22, ventral; 23, posterior; 24, lateral. Escalas: Figs 14-18 e 20-24, 0,1 mm; Fig. 19, $1 \mathrm{~mm}$. 
W. Levi, em 1969 (vide figs Levi, 2007). KeyserLing, 1892:157, est. 8 , fig. 115 .

Araneus albiventer; Petrunkevitch, 1911:278

Metazygia albiventer; Mello-Leitão, 1943:186.

Eustala albiventer; Levi, 1991:178; Platnick, 2010.

Epeira sanguinosa Keyserling, 1893:225, est. 11, figs 167,

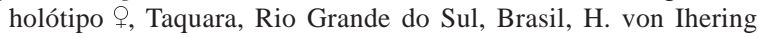
col. Depositado no The Natural History Museum, Londres e examinado por H. W. Levi, em 1975 (vide figs Levi, 2007). Syn. nov.

Araneus sanguinosus; Petrunkevitch, 1911:314.

Eustala sanguinosa; Roewer, 1942:766; Platnick, 2010.

Nota. Eustala albiventer não foi encontrada no amplo material examinado da planície costeira do Rio Grande do Sul, onde se encontra a localidade-tipo desta espécie. A ilustração do epígino de E. albiventer foi efetuada em vista póstero-ventral por KEYSERLiNG (1884, 1892) e LEVI (2007). Na correta posição ventral e posterior, o epígino se apresenta como em E. sanguinosa. A associação de machos e fêmeas foi realizada em material coligido em Rio Grande, Palmares do Sul, Capivari do Sul e Porto Alegre.

Diagnose. O palpo do macho (Figs 20, 21) de Eustala albiventer distingue-se daqueles com apófise terminal longa e afilada, pela forma do condutor similar a um cantil de couro, em vista ventral (Fig. 21). Fêmeas separam-se pelo epígino (Figs 22-24) mais largo do que longo com abrupto escapo, estreito, com estrias inconspícuas, em vista ventral (Fig. 22) e, em vista posterior (Fig. 23), pela placa mediana estreita.

Descrição. Macho (MCN 13818). Carapaça amarela, região cefálica demarcada por pigmento branco. Esterno amarelo com margens pretas. Pernas amarelas com bandas castanho-claras. Abdômen subtriangular, ápice posterior arredondado e dorso com fólio; ventre castanho-claro, esmaecido, com mancha branca mediana.

Medidas. Comprimento total 3,1. Comprimento da carapaça 1,6, largura 1,3. Pernas, fórmula 1243. Comprimento da perna I: fêmur 2,2; patela + tíbia 2,6; metatarso 1,7 ; tarso 0,7 ; comprimento total 7,2 . Patela + tíbia II 1,8; III 1,0; IV 1,5.

Fêmea (MCN 45697). Coloração como a do macho. Esterno com pigmento branco junto à margem anterior. Pernas amarelas, somente tíbias e metatarsos posteriores com bandas castanhas. Abdômen subtriangular, com distinto ápice posterior e dorso reticulado de branco com fólio.

Medidas. Comprimento total 3,4. Comprimento da carapaça 1,2, largura 1,2. Pernas, fórmula 1243. Comprimento perna I: fêmur 1,7 ; patela + tíbia 2,2; metatarso 1,2; tarso 0,6; comprimento total 5,7. Patela + tíbia II 1,$7 ;$ III 0,8 ; IV 1,4 .

Variação. Machos (n=5): comprimento total: 3,0-3,5; carapaça: 1,5-1,7; largura: 1,3-1,4. Fêmeas $(n=5)$ : comprimento total: $3,2-4,4$; carapaça: 1,2-1,7; largura 1,21,5. O colorido varia de amarelo-claro a castanho-escuro. A maioria das fêmeas tem pigmento branco irregularmente distribuído na carapaça e no esterno. O ventre geralmente é esmaecido. Nas fêmeas, o ápice posterior do abdômen pode ser bem pronunciado. $O$ escapo pode ser mais longo ou mais curto e fino; na vista posterior, as placas laterais podem ser arredondadas ou, às vezes, assimétricas no mesmo exemplar.
Distribuição. Brasil (Santa Catarina e Rio Grande do Sul) (Fig. 3).

Material examinado. BRASIL, Santa Catarina: Araranguá (Morro dos Conventos), +, 18.II.1985, A. D. Brescovit col. (13147); Rio Grande do Sul: Vacaria, O', 12.X.1994, L. Moura col. (26161); Cambará do Sul, , 22.XII.1976, A. A. Lise col. (4956); 5 ठ', , 25.XI.1993, M. A. L. Marques col. (24326); ㅇ, 1921.XII.1994, A. B. Bonaldo col. (25981); , 13.I.1994, N. Silveira col. (24916); Muçum, ơ' 02.III.1994, A. D. Brescovit col. (12111); Canela, Ơ, 5 \%, 06.III.1966, A. A. Lise col. (10086, 45739); São Francisco de Paula, 2 ot $^{7}$, , 05.XI.1998, L. Moura col. (29715, 29722); 2 O', 01-04.II.1999, L. Moura col. (30517); O', 04.XI.1998, A. H. Silva col. (29709); Santa Maria, O, 02.XI.1985, A. D. Brescovit col. (14582); Montenegro, , 20.XII.1977, V. Pitoni col. (7652); Maquiné, + , 30.V.2008, R. B. Moura col. (44250); São Leopoldo, + , X.1972, C. J. Becker col. (27594); Triunfo, 2 ㅇ, 02.VI.1977, A. A. Lise col. (5701); ㅇ, 24.X.1988, E. H. Buckup col. (17891); (Parque Copesul de Proteção Ambiental), O 30.VII.2003, R. Ott \& A. Barcellos col. (36012); ㅇ, 28.XI.2002, R. S. Araújo col. (34988); 2 ơ, 06.I.2005, R. Ott col. (38259); Praia do Curumim, O', 02.II.1977, C. J. Becker col. (3997); Capivari do Sul, 3 ơ, 11 ㅇ, 20.V.2004, Equipe Probio col. (37372, 37396); Gravataí, + , 15.III.1999, J. Soledar col. (30563); 3 +, 23.III.1983, H. A. Gastal col. (11496); Eldorado do Sul, + , 12.X.1998, L. Moura col. (29743); 9 , 29.X.1998, A. B. Bonaldo col. (29664); (Parque Estadual do Delta do Jacuí), ơ,, , 05-07.I.2000, A. B. Bonaldo col. (31863, 45700); Porto Alegre (Reserva Biológica do Lami), ơ, IV.2000 (37698); 2 ᄋ, VI.2000 (37701); 2 ơ, o, VIII.2000 (37699, 37702, 37723); ㅇ, 19-22.II.2001 (37703); O', 11-13.V.2001 (37724); ค, 13, 14.VI.2001 (37694); O', 9, 10.VIII.2002 (37700); 2 ơ, 5 +, 13, 14.VIII.2001 (37704, 37695); 2 ๆ, 16.X.2001

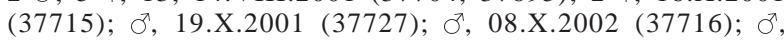
11.XII.2002 (37717); ㅇ, 01, 02.II.2002 (37705), todos coletados por E. L. C. Silva \& C. E. Ferro;, , VIII.2000, L. E. C. Schmidt col. (38149); (Arroio do Salso), 8 \%, 17.IX.2003, R. Ott \& I. Heydrich col. (36350); Viamão, O’, 30.III.1977, E. H. Buckup col. (5572); (Estação Experimental Águas Claras), 2 o', 18.X.1985, A. D. Brescovit col. (14461); 4 \&, 01.IV.2000, A. B. Bonaldo col. (32936); (Itapuã), , 15.I.2002, H. P. Romanowiski col. (45404); Palmares do Sul, ơ, 21 q, 07.IV.2003, Equipe Probio col. (35267, 35464, 45697, 46997); 7 o', 3 क, 14.XI.2003, Equipe Probio col. (36624); (Ilha Grande, Lagoa do Casamento), 2 ค, 08.IV.2003 (35384); 4 ㅇ, 09.IV.2003 (35391); ㅇ, 10.IV.2003 (35284); ठ, 2 ㅇ,

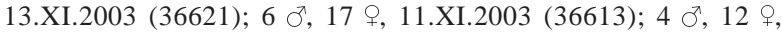
12.XI.2003 (36616), todos coletados pela Equipe Probio; Barra do Ribeiro, + , 13.V.2003, Equipe Probio col. (35587); ơ, $q$, 16.XII.2003, Equipe Probio col. (36763); Tapes, 20 , 6 ㅇ, 14.V.2003, Equipe Probio col. $(35544,35545,35547,35553$, 36779); ㅇ, 15.V.2003, R. S. Araújo col. (35676); 2 o', +, 15.V.2003, Equipe Probio col. $(35558,37304)$; O,, , 19.XII.2003, Equipe Probio col. (36794, 37307); Tavares (Parque Nacional da Lagoa do Peixe), +, 16.IV.1991, N. Silveira col. (20849); São Lourenço do Sul, , , 25.I.1976, P. E. Braum col. (3353); Cristal,, , 20.IV.2009, E. N. L. Rodrigues col. (46653); Pelotas, O', 26.IX.1975, A. A. Lise col. (3454); Capão do Leão (Horto Botânico Irmão Teodoro Luís), क, 10.IX.2001, E. N. L. Rodrigues col. (44422); Arroio Grande, O', १, 23.IX.2008, E. N. L. Rodrigues col. (46644); Rio Grande, , 09.II.1986, E. H. Buckup col. (14969); (Estação Ecológica do Taim), ơ, 2 , 01.XI.1980, A. A. Lise col. (9320); , 15.X.1985, H. A. Gastal col. (13529); ơ, ९, 15, 16.X.1985, M. A. L. Marques col. (13482, 13771); + , 16.X.1985, A. A. Lise col. (13793); $0^{7}$ 16.X.1985, C. J. Becker col. (13818); Ơ, 2 ᄋ, 17.X.1985, E. H. Buckup col. (13654, 13658); O', , 28.XI.1985, M. Rosenau col. (13860, 13884); O', 02.XII.1986, M. Rosenau col. (44942); O, 12.XII.1985, A. A. Lise col. (14197); $ণ$, 17.XII.1985, A. A. Lise col. (14226); 3 ㅇ, 07, 08.IV.1986, M. Rosenau col. (14690, 14903); 2 o', 2 क, 08-10.IV.1986, E. H. Buckup col. (14660, 14764, 14766, 14966); 2 क, 08.IV.1986, A. A. Lise col. (14909); 2 ơ, ㅇ, 09, 10.IV.1986, M. A. L. Marques col. (14645, 15001, 15002); 2 ㅇ, 01.IX.1986, A. A. Lise col. (15659); đ', ㅇ, 01.IX.1986, M. Rosenau col. $(15671,15672)$; ơ, ㅇ, 02.IX.1986, M. A. L. Marques col. (15631); 2 o,, , 02.IX.1986, A. A. Lise col. (15652, 15654); 2 , 02.IX.1986, E. H. Buckup col. (15679); ㅇ, 15.X.1985, H. A. Gastal col. (13606); ㅇ, 15.X.1985, M. A. L. Marques col. (13546); $3 \sigma^{\top}, 5$ 
ㅇ, 15.X.1985, A. A. Lise col. (13668); 2 , 15.X.1985, M. Rosenau col. (13728); ㅇ, 15.X.1985, C. J. Becker col. (13795); 2 đ', 4 , 16.X.1985, E. H. Buckup col. (13507-13509); 2 +, 16.X.1985, M. Rosenau col. (13742, 13743); ㅇ, 16.X.1985, H. A. Gastal col.

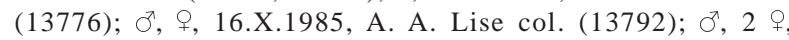
16.X.1985, C. J. Becker col. (13815, 13816); O’, 04.XI.1986, E. H. Buckup col. (15955); 2 9, 04.XI.1986, M. A. L. Marques col. (15976, 15977); 2 O', 07.XI.1986, H. A. Gastal col. (15710); O’, 6 ㅇ, 02.XII.1986, M. Rosenau col. (16232, 16233, 16549); 우, 02.XII.1986, M. C. Moraes col. (16264); 3 o', 8 †, 02.XII.1986, A. D. Brescovit col. (16246); 3 ơ, 3 \%, 02.XII.1986, M. A. L. Marques col. (16242); 2 ơ, 2 ㅇ, 04.XII.1986, A. D. Brescovit col. (16292); ठ, 04.XII.1986, M. A. L. Marques col. (16095); ठ 2 , 04.XII.1986, M. C. Moraes col. (16194, 16195, 16402); 4 o’, 4 ?, 04.XII.1986, M. Rosenau col. (16321); 3 ơ, 7 9, 04.XII.1986, E. H. Buckup col. (16329); 2 ○’, 2 ㅇ, 12.XII.1986, A. A. Lise col. (14223); Santa Vitória do Palmar (Estação Ecológica do Taim), 3 ㅇ, 26.XI.1985, M. Rosenau col. (14046, 14047); 5 ơ, 5 , 26.XI.1985, M. A. L. Marques col. (14121, 14127, 14128); + , 27.XI.1985, H. A. Gastal col. (14034); O', 27.XI.1985, C. J. Becker col. (14003); 2 ơ, 12 \&, 09.IV.1986, M. Rosenau col. (14825, 14826); o', 8 +, 09.IV.1986, M. A. L. Marques col. (14834, 14835); 2 ơ, 3 , 09.IV.1986, A. A. Lise col. (14864, 14943); 6 , 09.IV.1986, E. H. Buckup col. (14872); О’, 05.X.1986, E. H. Buckup col. (14871); ơ, 02.IX.1986, M. Rosenau col. (15715); 2 , 02.IX.1986, A. A. Lise col. $(15759,45384)$; O', 02.IX.1986, M. A. L. Marques col. (15719); ㅇ, 10.IX.1986, M. Rosenau col. (14875); 2 †, 02.XII.1986, C. J. Becker col. (16460); Oð, 02.XII.1986, E. H. Buckup col. (16251); 2 ơ, 13 ㅇ, 03.XII.1986, M. A. L. Marques col. (16407, 16418); 2 ค, 03.XII.1986, M. C. Moraes col. (16433); 2 , 03.XII.1986, M. Rosenau col. (16427); 2 , 03.XII.1986, E. H. Buckup col. (16445).

\section{Eustala taquara (Keyserling, 1892)} (Figs 4, 25-29)

Epeira taquara KeyserLing, 1892:143, est. 7, fig. 105, holótipo 9 , Taquara, Rio Grande do Sul, Brasil, H. von Ihering col., depositado no The Natural History Museum, Londres e examinado por $\mathrm{H}$. W. Levi em 1975 (vide figs Levi, 2007).

Araneus taquara; PetrunKevitch, 1911:318.

Eustala taquara; Mello-LeitÃo, 1919:16; Roewer, 1942:766; BonNet, 1956:1841; Platnick, 2010.

Eustala ulecebrosa; Podgaiski et al., 2007:6, tab. 1 (examinados, identificação errônea).

Diagnose. Machos de Eustala taquara distinguem-se das espécies similares com condutor subretangular em forma de "telhado" anterior, em vista ventral (Fig. 26), pela distinta apófise terminal com uma flexão em sua metade apical e pela projeção tegular semiquadrangular, em vistas mesial e ventral (Figs 25, 26). O epígino (Figs 27-29) distingue-se pelo escapo com prolongamento apical largo e arredondado e pela placa mediana com bordas laterais projetadas lateralmente, em vista ventral (Fig. 27).

Descrição. Macho (MCN 34100). Carapaça amarela. Esterno amarelo com margem acinzentada. Pernas amarelas com bandas castanho-claras. Abdômen oval, mais longo do que largo; dorso reticulado de branco com fólio castanho-escuro; ventre amarelo-claro, com larga faixa mediana castanha, desde a fenda epigástrica até as fiandeiras, mancha branca mediana no centro.

Medidas. Comprimento total 4,8. Comprimento da carapaça 2,2, largura 1,7. Pernas, fórmula 1243. Comprimento da perna I: fêmur 3,3; patela + tíbia 3,7; metatarso 2,4 ; tarso 0,9 ; comprimento total 10,3 . Patela + tíbia II 2,7; III 1,4; IV 2,6.
Fêmea (MCN 46650). Abdômen subtriangular, colorido como o do macho.

Medidas. Comprimento total 5,3. Comprimento da carapaça 2,3, largura 1,7. Pernas, fórmula 1243. Comprimento da perna I: fêmur 2,9; patela+tíbia 3,4; metatarso 2,0; tarso 0,8 ; comprimento total 9,1. Patela + tíbia II 2,7; III 1,5; IV 2,0.

Variação. Machos $(\mathrm{n}=5)$ : comprimento total: 4,3-4,8; carapaça: 1,9-2,3; largura: 1,7-2,1. Fêmeas $(n=5)$ : comprimento total: 5,3-10,9; carapaça: 2,3-2,5; largura: 1,71,9. O colorido do dorso do abdômen varia entre os espécimes: o fólio pode estar bem demarcado, interrompido, esmaecido, com aparência de um escudo e pode ter mancha castanha arredondada central ou em cada lateral posterior.

Nota. Machos e fêmeas foram coletados juntos em várias localidades do Rio Grande do Sul.

Distribuição. Brasil (do Rio de Janeiro até o Rio Grande do Sul) (Fig. 4).

Material examinado. Rio de Janeiro: (Parque Nacional da Serra do Bocaina), 2 9, 14.V.1991, N. Silveira col. (21082, 21083); São Paulo: Mogi das Cruzes, 2 , 11, 12.V.1991, N. Silveira col. (21077, 21091); Paraná: Três Barras do Paraná, 3 O’, 3 ㅇ, 20-27.II.1993, A. B. Bonaldo col. (22997, 45383, 44384); Morretes, O', 28, 29.X.1995, A. B. Bonaldo col. (26721); Rio Azul, 5 9, 03.IV.1993, R. Boçon col. (23609, 23610); Quatro Barras, + , 02.IV.1995, UFPR col. (27233); Curitiba, 2 , 10.IV.1987 (16917); ㅇ, 01.XII.1990 (20619), ambos coletados por A. D. Brescovit; Guarapuava, + , 22.XI.1987, A. D. Brescovit col. (17104); Almirante Tamandaré, 3 9, 05.IV.1987, A. D Brescovit col. (16948, 16949); Pinhão, 6 o, 3 ㅇ, 31.VIII01.IX.1996, A. B. Bonaldo col. (27701); Santa Catarina: Concórdia, O', 24.I.2008, M. de Luz col. (44445); (Estrada Concórdia-Seara), O’, 2 , 30.I.1996, A. B. Bonaldo \& A. Kury col. (27242, 27243); Rancho Queimado, 2 O’, 2 , 13-15.I.1995, L. Moura col. (26331, 26333); 3 \&, 13-15.I.1995, A. B. Bonaldo col. (26769); ठ', 15, 18.XI.1993, L. Moura col. (44370); 5 ठ', 3 +, 08-11.X.1994, A. B. Bonaldo col. (26174, 26181); (Estrada Nova Teutônia-Itá), + , 01.II.1996, A. B. Bonaldo et al. col. (27138); Rio Grande do Sul: Derrubadas (Parque Estadual do Turvo), $2 \sigma^{7}, 17$ क , 27-31.X-01.XI.2003, (37542, 38107, 38714); $0^{7}, 8$ ㅇ, 04-08.V.2004 (38130); 4 or, 11 ㅇ, 19-22.X.2004 (38609, 35685, 38688); , 25.IV.2005 (39171), todos coletados por R. Ott et al.; (Salto do Yacumã),, 11.IX.1990, N. Silveira col. (19988); Salto do Jacuí, 2 ơ, ㅇ, 19.X.1998, A. B. Bonaldo col. (29642); Cambará do Sul (Área da Preservação Celulose Cambará), +, 19-21.XII.1994, L. Moura col. (44894); Júlio de Castilhos, O’, 22.X.1998, A. B. Bonaldo col. (30602); Estrela Velha, 2 O', 3 q, 20, 21.X.1998, A. B. Bonaldo col. $(29545,29547,29569$, 29572); +, 20.X.1998, A. H. Silva col. (29577); Salto do Jacuí, 2 ơ, o, 19.X.1998, A. B. Bonaldo col. (29642); Roca Sales, ơ, 2 ㅇ, 24.V.1986, A. D. Brescovit col. (45415); Encantado, 3 o', 2 ㅇ, 21.II.1985, A. D. Brescovit col. (14498, 46395); 3 ơ, 우, 21.IX.1985, A. D. Brescovit col. (14500); Canela, 2 o, 8 ㅇ, 2325.XI.1998, L. Moura col. (45719); , 15.XII.1999, A. Franceschini col. (31766); São Francisco de Paula, ơ, 6 +, 1922.III.1998, L. Moura col. (29201); O’, 04.XI.1998, L. Moura col. (29706); O', 2 9, 04.XI.1998, A. H. Silva col. (29707, 45417); o', 6 9, 04, 06.XI.1998, A. B. Bonaldo col. $(45718,29669)$; O’, 2 q, 19.XI.1997, E. H. Buckup col. (28777, 28778, 28822); ơ, of, 01-04.I.1999, L. Moura col. (30516); o', 10 +, 01-04.II.1999, A. H. Silva col. (45717, 46394); 3 o , +, 18.XI.1997, M. A. L. Marques col. $(28725,28726) ; 4$ ㅇ, 03.XI.1998, L. Moura col. (29733); Candelária (Cerro do Botucaraí), ơ, ㅇ, 05-09.II.2001, A. Franceschini col. (33602, 33604); Parobé, O', 31.VII.2007 (46464); + , 17.IX.2007 (46463); 4 O', 2 ㅇ, 18.XII.2007 (46466); 2 o', ․, 29.I.2008 (46465); ठ 25.XII.2008 (46648); ㅇ, 25.IV.2009 (46650); o', 06.VI.2009 (46651), todos coletados por E. N. L. Rodrigues; Maquiné, O", 18.IX.2007 (46468); ○’, 28.XII.2008 (46639); ㅇ, 22.III.2009 (46640), todos coletados por E. N. L. Rodrigues; Novo Hamburgo, 
오 07.X.1985 (14269); 우 04.XI.1985 (14353); 오 31.III.1986

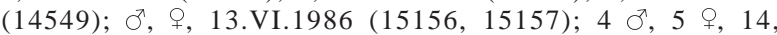
28.VII.1986 (15347, 15360, 15464-15467), todos coletados por C. J. Becker; São Leopoldo, 2 9, X.1973, C. J. Becker col. (45720); O. 17.XII.1985, C. J. Becker col. (14211); ㅇ, 12.VI.1992, A. B. Bonaldo col. (24759); O', 12.VI.1992, A. D. Brescovit col. (24758); 2 o', ․, 13.VII.1992, A. C. Meyer col. (24737, 24738); Triunfo (Ilha dos Dorneles), 2 o', o, 23.VII.1986, M. Hoffmann col. (15380); (Parque Copesul de Proteção Ambiental), 3 ơ, 7 우 04.IV.1987, S. Scherer col. (16846, 16847); +, 23.IV.1987, M. A. L. Marques col. (16781); ㅇ, 23.IV.1987, M. E. L. de Souza col. (16784); ơ, \&, 30.XI.1987, M. A. L. Marques col. (17055, 17056); 2 ơ, 4 ㅇ, 24.X.1988, M. A. L. Marques col. (17890); 우, 08.XI.1988, M. H. Galileo col. (17931); 3 o, o, 12.I.1989, M. A. L. Marques col. (18049); ㅇ, 12.I.1989, M. H. Galileo col. (18062); o', 2 9, 12.I.1989, A. B. Bonaldo col. (18063); o', 2 ․, 21.IX.1989, M. A. L. Marques col. (18658, 18698); 5 o', 9 ค, 21.IX.1989, E. H. Buckup col. (18661); 4 \&, 24.X.1989, E. H. Buckup col. (18889, 45312); 4 O', 9 क, 24.X.1989, M. A. L. Marques col. (18891-18893); 6 of, 5 ㅇ, 28.X.1989, A. D. Brescovit col (45317); 6 o , 7 ㅇ, 25.I.1990, A. D. Brescovit col. (19381); 3 o 12.VI.1991, L. Moura col. (21152); 2 ơ, 2 ९, 30.VI.1993, L. Moura col. (23706); O', 08.I.1997, A. B. Bonaldo col. (28164); ㅇ. 14, 15.I.1997, L. Moura col. (28239); +, 14, 15.I.1997, A. Franceschini col. (28238); O, 23.V.2000, E. H. Buckup col. (32331); O', 05.VII.2000, M. A. L. Marques col. (32495); o', 10.X.2000, E. Borsato col. (33526); 2 O', 3 +, 09.VIII.2001, R. S. Araújo col. (33997, 33998); O’, +, 05.III.2003, R. S. Araújo col. (35084); o ,, , 05.III.2003, R. Ott col. (35108); 8 o , 9 , 29, 30.VII.2003, R. Ott \& A. Barcellos col. (35964, 35970, 35991, 36011, 36040); 2 o', 29.VII.2003, R. S. Araújo col. (36069); 2 o 29.VII.2003, T. Tavares col. (36022); 2 ơ,, , 21, 22.X.2003, A. Barcellos \& L. Schimidt col. (36470, 36514); 2 o', 3 ㅇ, 29, 30.IV.2003, R. Ott col. (35716); 3 \&, 25.V.2004, A. Barcellos col. (37339); 2 o', 4 +, 24.VIII.2004 (38173, 38174); ㅇ, 06.I.2005 (38247); $20^{7}, 2$ ㅇ, 01.III.2005 (39912), todos coletados por R. Ott et al.; , 15.III.2006, R. Ott col. (41299); 3 o', +, 18.IX.2006, R. Ott \& A. Barcellos col. (42083, 42084, 42152); 3 ơ, 오, 07.XII.2005, R. Ott col. (40108); O', 12.XII.2006, R. Ott \& A. Barcellos col. (42753); ㅇ, 28.V.2007, A. Barcellos col. (43401); $20^{7}$, , 21.VIII.2007, M. A. L. Marques col. (43485); 4 o", 31.VIII.2007, L. Schimidt col. (43538); 4 O', 4 ․, 12.XI.2007, M. A. L. Marques col. (43714); 4 ơ 6 क, 12.XI.2007, A. Barcellos \& L. Schimidt col. (43720); O', 14.II.2008, A. Franceschini col. (44000); 3 o', ㅇ, 17.III.2008, E. N. L. Rodrigues \& M. Pairet Jr. col. (43983); o', ㅇ, 03.IV.2008, M. Pasolius col. (44029); 2 , 03.IV.2008, A. Barcellos col. (44121); , 14.II.2008, R. Moraes col. (44002); ㅇ, 14.II.2008, L. Moura col. (44014); 4 ơ 3 ㅇ, 09.VII.2008, A. Barcellos col. (44169); 2 ơ, 2 †, 01.IX.2008, M. A. L. Marques col. (44367); O', + , 01.IX.2008, E. N. L. Rodrigues col. (45393, 45394); 4 o, 3 क, 11.XI.2008, A. Barcellos col. (44948); 2 +, 29.V.2009, E. N. L. Rodrigues col. (46145); (Parque Braskem de Proteção Ambiental, ex-Copesul), 3 ơ, 15.IX.2009, P. E. S. Rodrigues col. (46558); O', 4 9, 15.IX.2009, M. R. M. Poeta col. (46559, 46634); O, 15.IX.2009, M. A. L. Marques col. (46601); Gravataí, ơ, 05.XI.1989, R. A. Ramos col. (19155); , 25.XI.1998, R. S. Araújo col. (29802); 6 o , 25.XI.1998, J. Soledar col. (29835, 44895); 3 O', 3 ค, 25.XI.1998, M. A. L. Marques col. (44423, 46390); 2 o', 15.III.1999, M. A. L. Marques col. (45399); Eldorado do Sul (Parque Estadual Delta do Jacuí), 27.X.1998, A. B. Bonaldo col. (44893); ㅇ, 28.I.1999, A. B. Bonaldo col. (44902); Arroio dos Ratos, 2 ơ $^{7}$,, 01.VIII.1986, M. Hoffmann col. (15478); o', 2 \&, 01.VIII.1986, M. H. Galileo col. (15476); Guaíba, ㅇ, 11.II.2009, A. Barcellos col. (45900); Porto Alegre, O, 2 ㅇ, 17.IX.1997, A. Franceschini col. (28619); (Reserva Biológica do Lami), 3 o', 13, 14.VI. 2001 (44896); 우, 19-22.II.2001 (45416); O', 01, 02.II.2002 (37696), todos coletados por E. L. C. Silva \& C. E. Ferro; ơ, II.2000, L. E. C. Schmidt col. (37709); (Lomba do Pinheiro), , 03.IX.1989, R. Arruda col. (18628); (Parque Estadual Delta do Jacuí), +, 27.X.1998, A. B. Bonaldo col. (29760); Mariana Pimentel,, , 02.XII.1989, A. A. Lise col. (45313); Barra do Ribeiro, 16.XII.2003, Equipe Probio col. (36762); Cristal, ơ, ${ }^{\prime}$,
26.VII.2007 (46409, 46411); O, 11.IX.2007 (46410); 웅

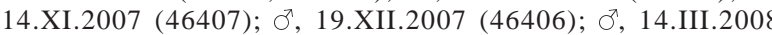
(46408); o, 21.VI.2008 (46405); o", 06.VIII.2008 (46655); ㅇ. 12.XI.2008 (46657); 3 o', 2 ค, 17.II.2009 (46654); +, 20. III.2009 (46656), todos coletados por E. N. L. Rodrigues; Pelotas, $20^{7}, q$, 15, 16.III.1996 (27448, 27449); 2 o', 3 ㅇ, 04-06.X.1996 (27781) o', 31.XII.1996 (28143); O, 3 ㅇ, 01-04.V.1998 (29394, 29395), todos coletados por L. Moura; Capão do Leão (Horto Botânico Irmão Teodoro Luís), ơ, 5 †, 21.V.2001, E. N. L. Rodrigues col (46398); Arroio Grande, +, 10.IX.2007 (46462); ơ, ㅇ, 10.III.2008 (46419); O', 15.XI.2009 (46647), todos coletados por E. N. L. Rodrigues; Rio Grande (Estação Ecológica do Taim), ơ , 17.X.1985, E. H. Buckup col. (44985); o, 14.XII.1985, A. A. Lise col. (45677); , 10.IV.1986, M. A. L. Marques col. (45318).

\section{Eustala photographica Mello-Leitão, 1944}

(Figs 5, 30-34)

Eustala photographica Mello-Leitão, 1944:329, figs 13, 14, holótipo +, Punta Chica, Buenos Aires, Argentina, Prosen col., depositado no Museo de La Plata (MLP 15955). Examinado por H. W. Levi em 1974 (vide figs Levi, 2007). Brignoli, 1983:270; Platnick, 2010

Diagnose. O palpo do macho de E. photographica (Figs 30,31) é semelhante aos de E. minuscula (Keyserling, 1892), E. orina (Chamberlin, 1916) e ao macho associado a E. mourei Mello-Leitão, 1947 (vide figs LEVI, 2007) pela apófise terminal laminar e apófise subterminal reduzida. Distingue-se de E. minuscula pela apófise subterminal com projeção espiniforme translúcida e das duas últimas pela forma e posição da projeção tegular (Figs 30, 31). Fêmeas distinguem-se pelo epígino (Figs 32-34) com placa mediana ampla e margem posterior larga quase reta, em vista ventral (Fig. 32); bordas das placas laterais aneladas e espessas, na vista ventral e lateral (Figs 32, 34); em vista posterior, placas laterais muito afastadas uma da outra e gradativamente convergentes para trás (Fig. 33).

Descrição. Macho (MCN 12485). Carapaça amarela, região cefálica com pigmento branco. Esterno preto. Pernas amarelas com bandas castanhas. Abdômen oval, mais longo do que largo, com ápice posterior distinto; dorso com padrão de coloração igual ao do espécimetipo (LEVI, 2007), preto com pigmento branco em faixa mediana longitudinal.

Medidas. Comprimento total 4,0. Comprimento da carapaça 2,0, largura 1,6. Pernas, fórmula 1243. Comprimento da perna I: fêmur 2,6; patela + tíbia 3,1; metatarso 1,9 ; tarso 0,8 ; comprimento total 8,4. Patela + tíbia II 2,2; III 1,2; IV 1,8.

Fêmea (MCN 12485). Coloração similar a do macho, exceto esterno cinza-escuro e abdômen subtriangular com faixa mediana branca mais curta.

Medidas. Comprimento total 4,6. Comprimento da carapaça 1,7, largura 1,5. Pernas, fórmula 1243. Comprimento da perna I: fêmur 2,2; patela + tíbia 2,7 metatarso 1,7; tarso 0,7; comprimento total 7,3. Patela + tíbia II 2,4; III 1,1; IV 1,9.

Variação. Machos $(n=5)$ : comprimento total: 3,7-4,4; carapaça: 1,9-2,2; largura: 1,6-1,7. Fêmeas $(n=5)$ comprimento total: 4,1-5,6; carapaça: 1,7-2,0; largura: 1,31,6. Carapaça amarela ou manchada de preto em menor ou maior quantidade, às vezes, com pigmento branco. A maioria dos espécimes examinados apresentava abdômen com fólio, exceto os de Almirante Tamandaré, PR, com 
faixa mediana longitudinal branca, semelhante a do espécime-tipo. Um exemplar com mancha arredondada castanha nas laterais posteriores do abdômen.

Nota. A espécie era conhecida apenas pela fêmea da Argentina. Machos e fêmeas foram colecionados juntos em várias localidades do sul do Brasil.

Distribuição. Brasil (Paraná, Rio Grande do Sul); Uruguai (Artigas); Argentina (Buenos Aires) (Fig. 5).

Material examinado. BRASIL, Paraná: Almirante Tamandaré, 2 O’, ㅇ, 22.IV.1984 (12402, 12485); ㅇ, 08.VIII.1984 (12499), todos coletados por E. C. Costa; Bom Retiro, + , 10.IV.1987, A. D. Brescovit col. (16916); Rio Grande do Sul: Roca Sales, ㅇ, 24.V.1986, A. D. Brescovit col. (15100); Cristal, 2 †, 19.XII.2007, E. N. L. Rodrigues col. (46413); Bagé, o, 10.I.1966, C. de Oliveira col. (45698); Arroio Grande, $९$, 24.VII.2007 (46418); , 30.I.2008 (46415); 2 ค, 13.VI.2008 (46414); ơ,,+ , 07.VIII.2008 (46642); 2 ơ, 2 ค, 23.IX.2008 (46643); ơ, 19.XII.2008 (46645), todos coletados por E. N. L. Rodrigues; URUGUAI, Artigas: Artigas, o’, 13,14.X.1995, L. Moura col. (26741).

\section{Eustala minuscula (Keyserling, 1892)}

(Fig. 6)

Epeira minuscula KeYserLING, 1892:140, est. 7, figs 103 a-e, síntipos $\mathrm{O}^{7}$,, , Rio Grande do Sul, Brasil, H. von Ihering col., depositados no The Natural History Museum, Londres e examinados por $\mathrm{H}$. W. Levi em 1973 (vide figs Levi, 2007).

Araneus minusculus; Petrunkevitch, 1911:304.

Eustala minuscula; Mello-Leitão, 1919:16; 1943:179; Bonnet, 1956:1841; Platnick, 1993:434; 2010.

Mangora minuscula; RoEwer, 1942:774.

Diagnose. O palpo do macho de Eustala minuscula (vide figs Levi, 2007), semelhante ao de E. photographica pela apófise terminal laminar, distingue-se pela proeminente projeção tegular sub-retangular, em vista mesial. Fêmeas separam-se pelo epígino campanuláceo com expansões laterais, basais (vide KeYserLING, 1892:140, est. 7, figs 103 a-e; Levi, 2007).

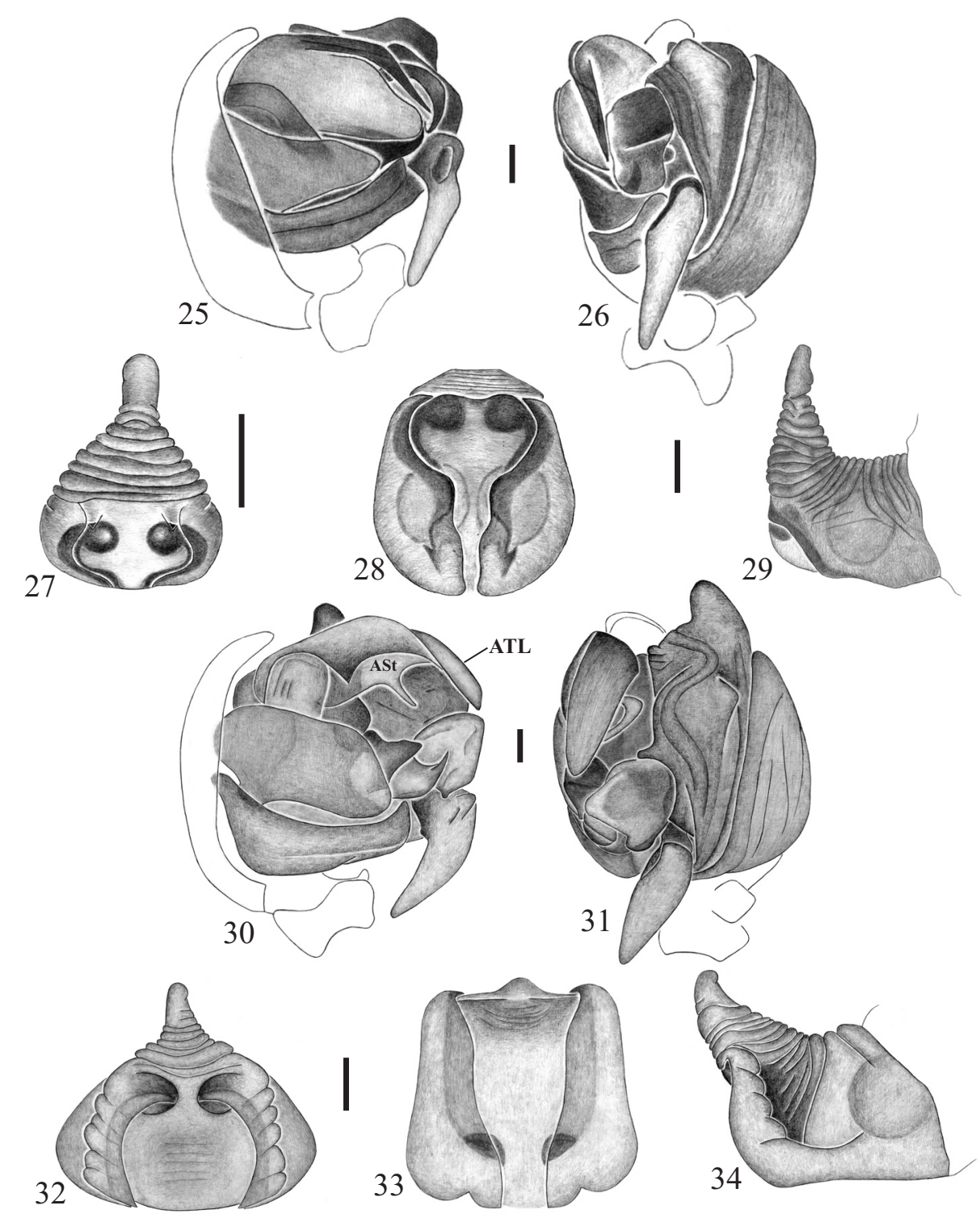

Figuras 25-34. Eustala taquara (Keyserling, 1892), palpo: 25, mesial; 26, ventral; epígino: 27, ventral; 28, posterior; 29, lateral. Eustala photographica Mello-Leitão, 1944, palpo: 30, mesial; 31, ventral; epígino: 32, ventral; 33, posterior; 34, lateral (ASt, apófise subterminal, ATL, apófise terminal laminar). Escalas: $0,1 \mathrm{~mm}$. 
Distribuição. Brasil (Santa Catarina e Rio Grande do Sul) (Fig. 6).

Material examinado. BRASIL, Santa Catarina: Rancho Queimado, +, 15, 18.XI.1993, A. B. Bonaldo col. (44371); 2 , 15 , 18.XI.1995, L. Moura col. (26768); Rio Grande do Sul: Vacaria, 2 ơ, + , 14.I.1974, A. A. Lise col. (10511); Bom Jesus,, , 21.XII.1987 (17085); 7 ㅇ, 24.III.1989 (18459, 18461, 45311); 2 ㅇ, 2831.III.1998 (29281), todos coletados por A. B. Bonaldo; Cambará do Sul, , 09.I.1976, A. A. Lise col. (4047); , 16.VI.1983, A. A. Lise col. (11727); o', 25.XI.1993, M. A. L. Marques col. (24324); o', 11-13.IV.1994, M. H. Galileo col. (25413); (Itaimbezinho), o’, 27.IV.1985, A. A. Lise col. (46381); São Francisco de Paula (Floresta Nacional),, , IV.2001, R. Baldissera col. (35235); Estrela Velha,, , 20.X.1998, A. B. Bonaldo col. (29623); Campo Bom, + 22.VII.1986, C. J. Becker col. (15430); Montenegro (Centro Experimental da ULBRA), ơ, 31.VIII.2008, A. P. O. Brendel col. (44910); Candelária (Serro do Botucaraí), 3 ㅇ, 05-09.II.2001 (46382); +, 07.II.2001 (33623), ambos coletados por A. Franceschini; Rio Pardo, , 10.II.1969, A. A. Lise col. (7415); Capão da Canoa, ơ, 19.I.1986, A. A. Lise col. (14336); Triunfo (Ilha dos Dorneles), ơ, + , 23.VII.1986, M. E. L. Souza, A. D. Brescovit col. (15379, 15369); Canoas, ơ, 13.XII.1990, M. A. L. Marques col. (45381); Cachoeirinha (Estação Experimental do Arroz), o', 05.XI.2004 (39114); o', 2 ㅇ, 06.II.2005 (39137, 39121), todos coletados por E. N. L. Rodrigues; Gravataí, 2 \%, 25.XI.1998, J. Soledar col. (29834); , 25.XI.1998, M. A. L. Marques col. (29798); +, 15.III.1999, M. A. L. Marques col. (30561); Charqueadas, , 15.IV.1982, E. H. Buckup col. (10100); Porto Alegre (Reserva Ecológica do Lami), q, 10, 11.XII.2001, E. L. C. Silva \& C. E. Ferro col. (37714); (Jardim Botânico), +, 09.XII.1993, A. Franceschini col. (24497); Guaíba, ㅇ, 01.I.1989 (18008); 3 o’, ㅇ, 24-27.XII.1992 (22644); 2 ơ, 01.I.1993 (22688), todos coletados por A. B. Bonaldo; Sertão Santana, , 22.III.1973, Z. M. Rosa col. (786); Rio Grande (Estação Ecológica do Taim), O’, 17.X.1985 (13655); ơ, 08.IV.1986 (14767); ㅇ, 04.XII.1986 (45315), todos coletados por E. H. Buckup.

\section{Eustala saga (Keyserling, 1893) (Fig. 7)}

Epeira saga KEYsERLing, 1893:253, est. 13, figs 188 e 188 a. Síntipos O do Uruguai e $\sigma^{7}$ do Rio Grande do Sul, Brasil, H. von Ihering col., depositados no The Natural History Museum, Londres e examinados por H. W. Levi em 1975 (Levi, 2007).

Araneus sagus; Petrunkevitch, 1911:313.

Eustala saga; Roewer, 1942:766, Platnick, 2010.

Diagnose. Eustala saga similar às espécies do grupo fuscovittata pelo abdômen alongado, separa-se destas espécies, principalmente de E. sagana (Keyserling, 1893) pela forma do condutor com detalhes diferenciados em sua porção anterior e prolongamento posterior largo, em vista ventral. Fêmeas distinguem-se pelo escapo triangular com base projetada, nas três vistas (vide Keyserling, 1893, fig. 188; Levi, 2007).

Distribuição. Brasil (Bahia, São Paulo, Paraná, Santa Catarina e Rio Grande do Sul) (Fig. 7). Uruguai (localidadetipo não especificada).

Material examinado. BRASIL, Bahia: Uruçuca, ơ, 26.XI.1977, J. S. Santos col. (21909); São Paulo: Mogi das Cruzes, , 12.V.1991, N. Silveira col. (21134); Paraná: Pinhão (UHE Segredo), O', 31.VIII.-01.IX.1996, A. B. Bonaldo col. (27702); Tijucas do Sul, 오 XI.1979, Hoffmann \& Carvalho col. (8851) Santa Catarina: Concórdia, ơ, 24.I.2008, M. de O. Luz col. (44454); Governador Celso Ramos (Passo das Gaivotas), o , 5 ㅇ, 10-26.II.1993, L. Moura col. (22895); Rancho Queimado, $\odot, 8-$ 11.X.1994, A. B. Bonaldo col. (26180); 3 o', 13-15.I.1995, W. Koch col. (26334); 3 +, 15-18.XI.1995, A. B. Bonaldo col. (26775); , 15-18.XI.1995, L. Moura col. (26776); Rio Grande do Sul:
Derrubadas (Parque Estadual do Turvo), Ơ, 15.I.1985, A. A. Lise col. (12924); Machadinho, O', 15.II.1989, A. B. Bonaldo col (18216); Bom Jesus, ㅇ, 28-31.III.1998, C. Duckett col. (29297); Cambará do Sul, O', 25.XI.1993, M. A. L. Marques col. (24328); (Itaimbezinho), 3 ㅇ, 27.IV.1985, A. A. Lise col. (13271); (Área de Preservação Celulose Cambará), ㅇ, 19-21.XII.1994, L. Moura col. (25984); O', 19-21.XII.1994, M. H. Galileo col. (26046); Caxias do Sul, , 04.XI.1994, A. Franceschini col. (25903); Roca Sales, Ơ, 24.V.1986, A. D. Brescovit col. (15101); Salto do Jacuí, 우, 26.X.1999, A. Franceschini col. (31515); o', 2 ㅇ, 19.X.1998, A. B Bonaldo \& L. Moura col. (29639, 29640); Estrela Velha, 2 , 06.V.1998, M. A. L. Marques col. (29344, 29362); O', 28.X.1999, A. B. Bonaldo col. (31524); ㅇ, 07.III.2001, R. Ott col. (33665); ㅇ, 30.X.2001, A. Franceschini col. (45612); São Pedro do Sul, ㅇ, 11.I.1985, A. A. Lise col. (12922); Canela, 3 ở, 2 , 03, 07.X.1967, A. A. Lise col. $(525,10118,10481,21921)$; $\sigma^{7}$, 27.X.2000, E. H. Buckup col. (33319); São Francisco de Paula, Ơ', 2 ९, 19-22.III.1998, L. Moura col. (29207, 29208); O', 26.XII.2003, E. L. C. Silva col. (36698); ㅇ, 18.XI.1997, E. H. Buckup col. (28727); O’, 05.XI.1998, L. Moura col. (29714); O', 04.XI.1998, A. B. Bonaldo col. (29704); Igrejinha, O', 23.XI.1983, E. H. Buckup col. (11836); (Tainhas), 웅 31.XII.2003, E. L. C. Silva col. (36294); Santa Maria, 2 ㅇ, 09.V.1973, D. Link col. (1686); ơ, ㅇ, 02.XI.1985, A. D. Brescovit col. (14597); o', 08.VII.1986, M. Rosenau col. (10551); (Reserva Biológica do Ibicuí), ㅇ, 10.XII.1992, N. Silveira col. (22636); Restinga Seca, , 05.III.2004, J. L. Santos col. (38483); Candelária (Cerro do Botucaraí), ơ, 07.II.2001, A. Franceschini col. (33622); Montenegro, ㅇ, 01.IX.1977, H. Bischoff col. (6428); 3 우 03.IX.1977, E. H. Buckup col. (7121); O7, 05.IX.2003, V. Wolf et al. col. (37191); 3 o', 29.IX.1977, A. A. Lise col. (6645); 우 20.XII.1977, V. Pitoni col. (7648); São Leopoldo, + , X.1973, C. J. Becker col. (27602); Maquiné, O’, 09.V.2008, E. N. L. Rodrigues col. (46467); (Estação Experimental da Fepagro), ơ, ㅇ, 0608.III.1998, A. B. Bonaldo col. (29021); Praia do Curumim, $q$, 02.II.1976, C. J. Becker col. (3658); Triunfo, o’, 2 , 20.X.1977, A. A. Lise col. (6895); O', 27.X.1977, H. A. Gastal col. (7006); 12.V.1981, K. Zanol col. (9691); ㅇ, 12.V.1981, E. H. Buckup col. (9667); ㅇ, 12.V.1981, M. H. Galileo col. (9701); ơ, ㅇ, 23.IV.1987, M. A. L. Marques col. (16779); ㅇ, 24.X.1988, E. H. Buckup col. (17892); ơ, ㅇ, 28.XI.1989, M. A. L. Marques col. (19114); 우, 12.VI.1991, M. A. L. Marques col. (21158); O’, 11.IX.1992, M. A. L. Marques col. (22349); $ᄋ$, 24-27.XII.1992, M. A. L. Marques col. (7007); 3 ơ, + +, 25.I.1990, A. D. Brescovit col. (19390); (Ilha dos Dorneles), o', 23.VII.1986, E. H. Buckup col. (15382); Canoas, 2 ơ, 3 , 23.IV.1966, A. A. Lise col. (188); ㅇ, 24.I.1991, E. H. Buckup col. (20459); Cachoeirinha (Estação Experimental de Arroz), +, 16.XI.2004 (39133); + , 27.I.2005 (39230); O", 28.II.2005 (39481), todos coletados por E. N. L. Rodrigues; Gravataí, 3 ㅇ, 25.XI.1993, M. H. Galileo col. (29795); 웅 25.II.1998, J. Soledar col. (29831); o’, \&, Guaíba, ơ, +, 11.III.2009, L. Moura col. (45848); Porto Alegre (Reserva Biológica do Lami), ㅇ, 13, 14.VI.2001, (37729); Oో, , 13, 14.VIII.2001 (37708, 37720); o', 02.I.2002 (37728), todos coletados por E. L. C. Silva \& C. E Ferro; +, II.2005, L. E. C. Schmidt col. (37730); (Morro São Pedro), ơ, 26.IX.2003, R. Ott \& A. Barcellos col. (36358); (Arroio do Salso), o', 17.IX.2003, R. Ott \& A. Barcellos col. (36128) Guaíba, O, 01.I.1993, A. B. Bonaldo col. (22689); (Estação Experimental UFRGS), ㅇ, 03.I.1974, A. A. Lise col. (10509); ㅇ, 24-27.XII.1992, M. A. L. Marques col. (22645); Tapes, + , 16.VII.1973, P. R. Sogari col. (3688); Viamão, +, 13.V.1975, K Grosser col. (2915); + , 24.VII.1985, J. E. Henning col. (13324); 3 , 11-14.IV.1983, A. A. Lise col. (11542); Mariana Pimentel, ơ, 02.XII.1989, A. A. Lise col. (19083).

Agradecimentos. Ao doutorando Everton N. L. Rodrigues (PPG-Biologia Animal, UFRGS) pela assistência e sugestões na digitalização das imagens. Ao técnico de informática Diego Pascoal (FZB) pelo auxílio na elaboração das estampas. Aos consultores pelas importantes sugestões. À Diretora Executiva do MCN, Maria de Lourdes Abruzzi A. de Oliveira, pela disponibilização de equipamentos. Ao CNPq pela bolsa de Iniciação Científica (PIBIC - processo $\left.n^{\circ} 105695 / 2009-2\right)$ concedida à primeira autora 


\section{REFERÊNCIAS BIBLIOGRÁFICAS}

Bonnet, P. 1956. Bibliographia araneorum. Toulouse, Douladoure. v.2, pt.2, p.919-1926.

Brignoli, P. M. 1983. A catalogue of the Araneae described between 1950 and 1981. Manchester, Manchester University. $755 \mathrm{p}$.

Chickering, A. M. 1955. The genus Eustala (Araneae, Argiopidae) in Central America. Bulletin of the Museum of Comparative Zoology 112(6):391-518.

Keyserling, E. 1884. Neue Spinnen aus Amerikas. V. Verhandlung der k.k. Zoologisch-Botanischen Gesellschaft in Wien 33:649-684.

1892. Die Spinnen Amerikas. Nürenberg, Bauer \& Raspe v.4, pt.1, 208p.

1893. Die Spinnen Amerikas. Nürenberg, Bauer \& Raspe. v.4, pt.2, p.209-377.

Levi, H. W. 1977. American orb-weaver genera Cyclosa, Metazygia and Eustala north of Mexico (Araneae, Araneidae). Bulletin of the Museum of Comparative Zoology 148(3):61-127.

1991. The Neotropical and Mexican Species of the OrbWeaver genera Araneus, Dubiepeira, and Aculepeira (Araneae: Araneidae). Bulletin of the Museum of Comparative Zoology 152(4):167-315.

2007. Type species of araneid and tetragnathid genera. Harvard University. Disponível em: <http:// www.oeb.harvard.edu/faculty/levi>. Acesso em: 16.07.2008
Mello-Leitão, C. DE. 1919. Ligeiras notas sobre uma pequena collecção de araneidos do Museu Paulista determinados por E. Simon. Revista do Museu Paulista 9:1-17.

1943. Catálogo das aranhas do Rio Grande do Sul. Arquivos do Museu Nacional 37:148-245.

1944. Arañas de la provincia de Buenos Aires. Revista del Museo de La Plata Nueva Série 3(24):311-391.

Petrunkevitch, A. 1911. A synonymic index-catalogue of spiders of North, Central and South America with all adjacent islands, Greenland, Bermuda, West Indies, Terra del Fuego, Galapagos, etc. Bulletin of the American Museum of Natural History 29:1-791.

Platnick, N. I. 1993. Advances in Spider Taxonomy 19881991 with synonymies and transfers 1940-1980. New York, New York Entomological Society. 846p.

2010. The world spider catalog, version 10.5. American Museum of Natural History. Disponível em: <http:// research.amnh.org/iz/spiders/catalog/INTRO1.html>. Acesso em: 30.01.2010.

Podgaiski, L. R.; Ott, R.; Rodrigues, E. N. L.; Buckup, E. H. \& Marques, M. A. L. 2007. Araneofauna (Arachnida; Araneae) do Parque Estadual do Turvo, Rio Grande do Sul, Brasil. Biota Neotropica 7(2):1-15.

Rower, C. F. 1942. Katalog der Araneae von 1758 bis 1940. Bremen, Natura Bd.1, 1040p.

Simon, E. 1895. Histoire Naturalle des Araignées. Paris, Librairie Encyclopédique de Roret v.1, pt.3, p.488-761. 